\title{
ROL DEL ESTADO EN EL CONFLICTO DEL PUEBLO MAPUCHE
}

Rodrigo Lillo

El objeto de esta comunicación es presentar los elementos jurídicos que intervienen en la situación presentada como pueblo mapuche y expansión forestal. Elementos que se presentan como las manifestaciones de la relación conflictiva existente entre dos sistemas sociales opuestos/distintos, particularmente en lo referido a sus sistemas normativos. De esta forma, es posible abordar este dilema desde una perspectiva seria, y que nos habilite a plantear propuestas realistas. Nos situaremos desde la perspectiva del Estado, y la protección que brinda a las Tierras de los mapuches; luego, nos referiremos al caso de las empresas forestales, y su actuación respecto de las tierras indígenas; para, en definitiva, exponer acerca del conflicto específico del proceso por Ley de Seguridad del Estado que afecta a doce comuneros mapuches de las comunidades de Pichiloncoyan y Pililmapu, que constituye un ejemplo paradigmático del tema que nos ocupa; y acerca de que rol ha jugado aquí -nuevamente- el Estado.

\section{A. Protección de las Tierras indígenas y del TERRITORIO EN LA LEY INdígena.}

Pese a la nefasta actuación del Estado chileno a través de la historia, en su relación con los pueblos indígenas, este se plantea hoy desde una perspectiva distinta. En efecto, el Estado chileno se encuentra, actualmente y a partir del proceso provocado desde la sociedad civil durante las últimas décadas, comprometido en el respeto por la diversidad. Esto se manifiesta de diferentes maneras, verbi gracia:

․ El hecho de la aprobación de una nueva Ley indígena, que -a diferencia de las anteriores- no se refiere solamente a las tierras (o a la propiedad) de los indígenas ${ }^{1}$; si no que además se establecen reglas sobre la asociatividad, desarrollo, cultura, etc.; todo bajo los principios establecidos en el Art. $1^{\circ}$ del referido cuerpo legal.

ㄴ Los deseos no plasmados, presentados en el proyecto original de la CEP², en el sentido de consagrar la noción de pueblos indígenas y el concepto de territorios indigenas.

․ En este mismo sentido, esta nueva ley, y tal como lo señalan los parlamentarios que dieron aprobación a esta Ley (en las sesiones de discusión del proyecto), 
fue planteada como el pago de una deuda histórica, un mea culpa del Estado chileno en relación con el tratamiento que se ha dado a los Pueblos indígenas del pais.

ㄴ La discusión en el parlamento sobre la ratificación del Convenio 169 de la OIT.

ㄴ La consolidación de la doctrina de los DDHH y la percepción de que existe un orden público internacional ${ }^{3}$.

口 Asimismo, la idea de Nación única y uniforme que se presentó en los albores de la república, resulta hoy insostenible a la luz de la interpretación de nuestro ordenamiento realizada desde la Constitución Política (norma fundamental del ordenamiento jurídico chileno a la cual deben adecuarse el resto de las normas legales). Esto es asi, por la adscripción del orden vigente a valores como la dignidad de la persona, que da lugar al más primario de los derechos, que es el derecho a la igual consideración y respeto; y en general, la protección de los Derechos Humanos o fundamentales.

Ahora bien, estos principios se han intentado plasmar en definitiva, en un texto en que se reconoce la existencia de diversas etnias ${ }^{4}$ en Chile. Se estableció también en la Ley Indigena, el deber del Estado de "... proteger las tierras indigenas, velar por su adecuada explotación y por su equilibrio ecológico y propender a su ampliación». Todo esto, en razón de que se reconoce que para ellos (los indígenas) la tierra, es el fundamento principal de su existencia y cultura.

Con este objeto, se establecen diversos mecanismos jurídicos que tienden a la protección de la Tierra indígena. Estableciéndose de una manera expresa en el artículo 12, qué debe entenderse por tal. Alli se plantea, que para esta Ley, Tierra indigena es aquella que las personas o comunidades indigenas actualmente ocupan en propiedad o posesión. El que actualmente ocupen, en propiedad o posesión, tiene, para la ley winka (para el ordenamiento civil chileno), un sentido muy específico que no debemos soslayar. Que actualmente se ocupe en propiedad o posesión significa que, en el momento presente, el inmueble específico se encuentre inscrito en el Conservador de Bienes Raíces en favor de una persona o comunidad indígena (todo esto, de conformidad al sistema registral). No basta, entonces, ocupar una tierra con ánimo de dueño; será necesario también, que haya una inscripción de dominio respectiva. Así también se ha interpretado por los jueces. A su vez, el hecho de la inscripción ha de tener una justificación, esto es, un título que justifique esa adquisición. Pues bien, para que la Tierra sea indigena según la Ley, no sólo debe estar inscrita a nombre de un mapuche; si no que además el fundamento de esta inscripción debe corresponder a alguna de las que se enumeran en el artículo 12.

Así las cosas, la protección brindada a los Pueblos indigenas -en este aspecto, no es tan potente ni extensiva como se pudo pensar; y corresponde, en la práctica, a una protección sólo parcial.

$Y$ decimos que es más bien restringida, por las siguientes razones fundamentales:

3 Jus cogens.

Se rechazó el término "Pueblo", por un falso concepto e ignorancia al respecto de algunos parlamentarios. 
1. Dentro de la cosmovisión mapuche es complejo hablar de propiedad privada sobre la Tierra, tal como se describe en la ley winka ${ }^{5}$. La misma Ley indígena reconoce el carácter que para las etnias de Chile tiene la Tierra. La relación entre el hombre y la Tierra, parece no ser en la cosmovisión mapuche, una de apoderamiento, sino más bien una de pertenencia.

2. En segundo lugar, desde una perspectiva histórica, el espacio de influencia de los mapuches, siempre fue mayor al que ocupan en su sentido más estricto (donde viven) ${ }^{6}$, aquel respecto del cual se les ha "concedido" por el Estado títulos de dominio. De hecho, los títulos de merced entregados a fines de siglo pasado y comienzos de este, corresponden a terrenos que los mapuches ocupaban en este sentido estrecho; y por tanto mucho más reducidos de los que efectivamente ocupaban "de alguna otra manera".

Esta situación de desprotección o insuficiencia de la ley, ocurre a mi juicio, por la omisión que se hizo del término Territorio indigena. El concepto de territorio indigena era uno que se incluia en el capitulo segundo -»Reconocimiento y Protección de Tierras y Territorios Indígenas»- del proyecto original de Ley indígena elaborado por la CEPI. Se entendía por este: «el espacio social, demográfico, ecológico, cultural fundamental para la existencia y desarrollo de los pueblos indigenas. El territorio incluye el conjunto del sistema ecológico necesario para el desarrollo de estos pueblos, sin perjuicio de los derechos de propiedad construidos en esos espacios». Se establecía además, la protección de este territorio, a través de la institución del Territorio de Desarrollo Indigena; que implicaba entre otros:

Participación de las comunidades indígenas en la toma de decisiones respecto a planes, proyectos y programas de desarrollo económico, social y cultural que alli se implementaren; y por ende, la posibilidad de oponerse a ellos;

Derecho a beneficiarse materialmente de las actividades de explotación de los recursos naturales existentes en los territorios, a través de impuestos a las utilidades de las empresas.

Este concepto, y los efectos descritos, se eliminaron posteriormente en el pro ceso de formación de la ley.

Esta debilidad de nuestra legislación cobra importancia, atendiendo a que en el derecho internacional, se utiliza el concepto de territorio, que es el que se predica respecto de los Pueblos Indigenas en el Convenio 169. Además, porque, de acuerdo a un análisis territorial, las tierras objeto de despojo, no se encuentran protegidas por la ley indígena. En definitiva, el conflicto del Pueblo Mapuche, es el conflicto por su territorio.

Esta idea del Territorio indígena recogida por la OIT, que ha sido establecida en el Convenio 169, se presenta en la ll parte -Tierras-, artículo 13, acápite 2, señalando que "La utilización del término «tierras» en los artículos 15 y 16 deberá incluir el concepto de territorios, lo que cubre la totalidad del hábitat de las regiones que los pueblos interesados ocupan o utilizan de alguna otra manera «. 
Es decir el concepto o la idea de TERRITORIO, se aproxima mucho más a la realidad del pueblo mapuche, y permite una efectiva protección. La idea de un espacio de influencia, fundamental para su subsistencia, más que la de un inmueble inscrito a su nombre en el conservador de bienes raíces que provenga de algunos títulos o formas que el Estado ha usado para ceder, regularizar, entregar o asignar tierras a indigenas.

\section{B. Situación de las tierras que no se encuentran PROTEGIDAS POR LA LEY: CASO DE LAS TIERRAS OCUPADAS Y POSEIDAS POR LAS EMPRESAS FORESTALES.}

De esta forma, decimos que, aquellos Territorios que no son considerados Tierras Indígenas por la Ley indígena, no están dotadas de las protecciones establecidas en ella. Esto significa que alli, sus propietarios (es decir, aquellos que tienen inscrito este terreno a su nombre en el CBR, independiente de cuándo y cómo llegaron alli) podrán disponer arbitrariamente del destino y explotación del mismo. Al menos, en principio.

En estas circunstancias se hallan, todas aquellas Tierras que fueron despojadas a los indígenas y que actualmente se encuentran inscritas a nombre de terceros no-mapuche. Este despojo se produce a través de distintas épocas, en ocasiones -incluso- respetando las disposiciones legales vigentes (que siempre favorecieron esta afectación de los derechos de los indígenas sobre sus territorios); en distintas circunstancias; y con distintos agentes involucrados en este proceso. Una de las situaciones de despojo más reciente podriamos describirla de la siguiente manera:

Hacia la década del setenta se encontraba en plena ejecución el proceso de reforma agraria. En 1972 se dicta la Ley $N^{\circ} 17.729$, que es -de alguna manera- el antecedente de la actual Ley indígena ${ }^{7}$. Durante el breve período que tuvo vigencia este cuerpo legal, se recuperaron 68.381 hectáreas para los mapuches ${ }^{8}$. La recuperación de Tierras se hizo mediante mecanismos administrativos rápidos contemplados en la Ley 16.640 sobre reforma agraria, en combinación con la Ley №17.729 mencionada. Mediante expropiaciones, las comunidades lograron la restitución de Tierras correspondientes a sus títulos de merced, que les hubieran sido usurpadas. Otras, las menos, obtuvieron una ampliación de la cabida de su reducción ${ }^{9}$. De estas $68.381,987$ hectáreas favorecieron a 9 comunidades de la provincia de Arauco; en la $9^{\circ}$ región, 17.775 hectáreas en favor de 29 comunidades de la provincia de sión de la dictación del DL 2568, perdió su sentido original. 
Malleco y 7.190 hectáreas para 126 comunidades de la provincia de Cautín. Por su parte, en la $10^{\circ}$ región se rescataron 10.429 hectáreas que beneficiaron a 25 comunidades de la provincia de Valdivia, y 32.000 hectáreas a comunidades de la provincia de Osorno ${ }^{10}$.

En gran parte de estos casos, las comunidades indigenas conformaron cooperativas, a las que se les entregó materialmente un terreno, dictándose posteriormente la resolución expropiatoria por parte de la Corporación de la Reforma Agraria CORA. Sin embargo, con el acaecimiento del golpe militar se produjo el proceso de contrareforma; en virtud del cual, se revertió esta situación. Se persiguió a los miembros de las cooperativas, se les privó de los insumos necesarios para la explotación de las tierras, o simplemente se les reprimió. Los terrenos, que no tenían una inscripción de dominio a nombre de las cooperativas, fueron adquiridos judicial o administrativamente por terceros no indígenas, o directamente por la Conaf. Posteriormente - directa o indirectamente- pasaron a poder de empresas forestales, las que plantaron -o se aprovecharon-, de las plantaciones hechas por los mapuches beneficiados con las expropiaciones. La actividad forestal realizada por estas empresas fue, después, financiada en gran parte por el Estado, quien subsidió esta actividad de conformidad a lo establecido por el DL 701 sobre Fomento Forestal, del año 1974. En él se establece que el Estado bonificará hasta un $75 \%$ de los costos por cada superficie forestada. Además dispone, que los predios que se acojan a este régimen (de aptitud forestal), no les será aplicable la Ley $\mathrm{N}^{\circ} 16.640$ sobre reforma agraria.

En definitiva, el Estado financió la riqueza obtenida por estas empresas, en detrimento de las comunidades indígenas.

Esta misma situación ha ocurrido en la comuna de Lumako y Purén. Allí se encuentra ubicado el Fundo Pidenco, reivindicado por las comunidades indigenas Pichiloncoyán y Pililmapu. La hijuela oriente del Fundo Pidenco, de propiedad de Guillermo Uribe Barra, fue ofertada por este a CORA en 1971 (2 de Junio de 1971.). Posteriormente se adjudica a una cooperativa formada por personas indígenas, dictándose por CORA la respectiva resolución expropiatoria, la que se publica en el Diario Oficial del 15 de Julio del mismo año. Todo esto, de acuerdo a lo establecido en el artículo 33 de la Ley $\mathrm{N}^{\circ} 16.640$.

En el mes de Enero de 1975, el consejo de la Corporación resolvió reconsiderar y revocar el acuerdo de expropiación, como también el acuerdo por el cual se aprobó la tasación provisoria de las mejoras, y determinación provisional de la indemnización; esto fundado en que -según lo declarado unilateralmente por el expropiado-, se le habría presionado para formular la oferta; no obstante que de acuerdo a los términos de la carta dirigida por Uribe al vicepresidente de la CORA, se colige una voluntad libre y espontánea por parte del mismo.

Una vez que Uribe recupera este terreno, en 1980; lo transfiere en 4 millones a un tercero. Luego de una serie de transferencias, en 1990, es adquirido por Bosques Arauco S.A., en la suma de 391 millones de pesos. 


\section{Reacción del Estado frente a la REIVINdicación INdígena: PROCESO POR LA QUEMA dE CAMIONES EN LUMAKo.}

En el año 1996, dirigentes de la zona se organizan e inician un proceso de recuperación del Fundo Pidenco. Este proceso lleva a su punto más álgido, con la quema de tres camiones que transportaba madera de Bosques Arauco SA, ocurrido el día $1^{\circ}$ de Diciembre pasado. El mismo día, la gerencia de Bosques Arauco remite un fax al Intendente Regional, Sr. Oscar Eltit, solicitando protección e indicando la procedencia de un requerimiento por delitos de la Ley de Seguridad del Estado. Al dia siguiente la intendencia presenta el requerimiento ante la Corte de Apelaciones de Temuco, por los delitos contemplados en las letras c) y d) del artículo $6^{\circ}$ de la Ley sobre Seguridad del Estado.

Los delitos por los que se procesa -y acusa- a doce mapuches de las comunidades de Pichiloncoyán y Pililmapu están descritos en el artículo $6^{\circ}$ de la ley 19.253:

(c) Los que inciten, promuevan o fomenten, o de hecho y por cualquier medio, destruyan, inutilicen, paralicen, interrumpan o desafien las instalaciones, los medios o elementos empleados para el funcionamiento de servicios públicos o de utilidad pública o de actividades industriales, mineras, agrícolas, comerciales de comunicación, de transporte o de distribución, y los que, en la misma forma, impidan o dificulten el libre acceso a dichas instalaciones, medios o elementos;

d) Los que inciten, promuevan o fomenten, o de hecho $y$ por cualquier medio, destruyan, inutilicen impidan el libre acceso a puentes, calles, caminos u otros bienes de uso público semejantes;”

Más allá de que las conductas alli descritas no corresponden a lo ocurrido durante la primavera de 1997, lo que protegen estos tipos delictuales (bien jurídico) es el orden público. Ahora bien, si se entiende por orden público las bases fundamentales del orden institucional del Estado, entonces debemos concluir que todo delito atenta contra este orden público; sin embargo en esta ley penal especial, este concepto adquiere una significación más precisa y específica, como un atentado al sistema en su conjunto. Esto es un atentado a la seguridad del Estado.

En una sistema democrático, la protección de la seguridad del Estado no puede constituir un medio de represión, por el cual se pretenden llevar a cabo los deseos de la mayoria"1 . La seguridad del estado es un concepto acotado, no abarca cualquier cosa, sino que se refiere a la protección de los elementos que conforman el Estado. En el decir de Montealegre: «La seguridad de un Estado es su capacidad para afirmar su identidad fundamental en el tiempo y en el espacio ${ }^{12}$. Así, un Esta-

\footnotetext{
$11 \quad$ Esto es propio de un sistema totalitario. demia de Humanismo Cristiano, Santiago 1979, p. 87.
} 
do será seguro si cada uno de sus elementos, lo es. Para el territorio, su seguridad consiste en su integridad; para los habitantes, en la intangibilidad de sus derechos humanos fundamentales; para el gobierno en su estabilidad. En otro sentido, el Estado se verá afectado cuando se enfrente a una guerra, una insurrección o una violación, respectivamente.

Desde otra perspectiva, la seguridad del Estado tiene dos frentes: «el externo, en que puede verse afectada por la guerra y por la agresión militar, o por una agresión económica de tal entidad que ponga en riesgo el normal desarrollo de la vida colectiva; y el frente interno, en que la seguridad nacional se encuentra comprometida en los casos de tensión extrema o de pugna entre gobernantes y gobernados, traducida en situaciones de insurrección o rebelión o alzamiento revolucionario"13.

Observamos que frente a un conflicto como el que se presenta, con las características que se han descrito, es decir, frente a la reivindicación de espacio/territorio que los mapuches hacen, el Estado -a través de sus órganos- reacciona de manera desproporcionada y burda, respondiendo a lo que - aparentemente- ha sido su impronta histórica, su lógica de funcionamiento. Esto es, como un sujeto intolerante, temeroso a lo desconocido y absoluto.

\section{Conclusiones.}

La actuación desmedida del Estado, y más particularmente del Gobierno, sólo se pude entender, en cuanto pretende justificar su actuar en una protección de valores que estima superiores, a los que aqui se han mencionado. Interpretación que aparece como errónea, en el contexto de su ordenamiento autoimpuesto.

Esta confusión que se le provoca a los agentes del Estado, se justifica en cuanto el sistema normativo le otorga algunas pistas respecto de los valores a los que se debe brindar protección. En este sentido, no debe olvidarse que el sistema económico de mercado, que estimula y favorece la inversión y expansión de las forestales, es uno que se encuentra muy profundamente arraigado entre nosotros. Tanto asi, que el propio sistema institucional chileno destaca como principios primordiales (otorgándoles una categoría especial), el derecho de propiedad y la libertad para realizar cualquier actividad económica, sin que el Estado pueda restringirla arbitrariamente. Un sistema, que sobrevalora el hecho del consumo (que, en definitiva constituye el motor del sistema) y que privilegia el logro de ciertos grados riqueza, por sobre otros criterios; que prefiere, en suma, la utilidad de las acciones, por sobre la dignidad de las personas. De tal manera se ha interpretado este sistema de normas ${ }^{14}$, que se habla de orden público económico, para referirse a estas normas y principios; las cuales se encuentran en las propias bases de la institucionalidad. De allí, que se mire como proporcionada y adecuada la reacción frente a un atentado a este orden.

MARIO VERDUGO, EMILIO PFEFFER, HUMBERTO NOGUEIRA, Derecho Constitucional, Tomo II,Ed. Jurídica de Chile, p. 307. 
Un concepto tal de desarrollo, parece estar bastante asentado entre nosotros (los no-mapuche), pero es bastante discutible que estos mismos valores se encuentren asentados en la realidad mapuche. Es más, pareciera ser que son contradictorios.

Ocurre aparentemente entonces, que la contraposición entre estas dos formas sociales se manifiesta también en esta dimensión (opción de desarrollo); y que mientras no se adopte seriamente el camino del respeto a la diversidad, el conflicto de éstas, evolucionará indefectiblemente por una vía más agresiva y violenta, que pacifica. 